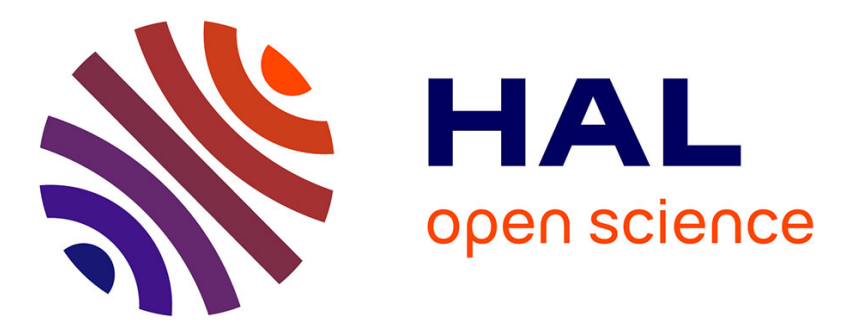

\title{
Optical anisotropy and photoluminescence temperature dependence for self-assembled InAs quantum islands grown on vicinal (001) InP substrates
}

B. Salem, J. Olivares, J. Brault, Christelle Monat, Michel Gendry, Guy Hollinger, H. Maaref, G. Guillot, G. Bremond

\section{To cite this version:}

B. Salem, J. Olivares, J. Brault, Christelle Monat, Michel Gendry, et al.. Optical anisotropy and photoluminescence temperature dependence for self-assembled InAs quantum islands grown on vicinal (001) InP substrates. Microelectronics Journal, 2002, 33, pp.579 - 582 . hal-02165357

\section{HAL Id: hal-02165357 \\ https://hal.science/hal-02165357}

Submitted on 3 Jul 2019

HAL is a multi-disciplinary open access archive for the deposit and dissemination of scientific research documents, whether they are published or not. The documents may come from teaching and research institutions in France or abroad, or from public or private research centers.
L'archive ouverte pluridisciplinaire HAL, est destinée au dépôt et à la diffusion de documents scientifiques de niveau recherche, publiés ou non, émanant des établissements d'enseignement et de recherche français ou étrangers, des laboratoires publics ou privés. 


\title{
Optical anisotropy and photoluminescence temperature dependence for self-assembled InAs quantum islands grown on vicinal (001) InP substrates
}

\author{
B. Salem ${ }^{\mathrm{a}, *}$, J. Olivares $^{\mathrm{a}}$, J. Brault ${ }^{\mathrm{b}}$, C. Monat ${ }^{\mathrm{b}}$, M. Gendry ${ }^{\mathrm{b}}$, G. Hollinger ${ }^{\mathrm{b}}$, H. Maaref ${ }^{\mathrm{c}}$, \\ G. Guillot ${ }^{\mathrm{a}}$, G. Bremond ${ }^{\mathrm{a}}$ \\ ${ }^{a}$ INSA de Lyon, LPM (UMR 5511 CNRS), 69621 Villeurbanne, France \\ ${ }^{\mathrm{b}}$ Ecole Centrale de Lyon, LEOM (UMR 5512 CNRS), Ecully, France \\ ${ }^{\mathrm{c}}$ Faculté des Sciences de Monastir, Monastir, Tunisie
}

\begin{abstract}
In this paper, we report on a detailed investigation of the effect of misorientated $\operatorname{InP}(001)$ substrates on the optical properties of InAs quantum islands grown by molecular beam epitaxy in the Stranski-Krastanow regime. Temperature-dependent photoluminescence and polarization of photoluminescence (PPL) are studied. PPL shows a high degree of linear polarization, near $40 \%$, for the sample grown on the substrate with $2^{\circ}$ off miscut angle towards [110] direction $\left(2^{\circ} \mathrm{F}\right)$ and only $16 \%$ for the sample grown on the substrate with $2^{\circ}$ off miscut angle towards [010] direction $\left(2^{\circ} \mathrm{B}\right)$. This result pointing out the growth of InAs quantum wires $(\mathrm{QWr})$ on $2^{\circ} \mathrm{F}$ substrate and of quasi-isotropic InAs quantum dots (QD) on $2^{\circ} \mathrm{B}$ substrate. The luminescence remains strong at $300 \mathrm{~K}$ as much as $36 \%$ of that at $8 \mathrm{~K}$, indicating a strong spatial localization of the carriers in the InAs QIs grown on $\operatorname{InP(001).~(C)~} 2002$ Elsevier Science Ltd. All rights reserved.
\end{abstract}

Keywords: Optical anisotropy; Photoluminescence; InP substrates; Quantum islands

\section{Introduction}

In recent years, much attention has been devoted to the fabrication and the characterization of self-assembled quantum dots (QDs) [1,2], which are important for both fundamental studies and optical applications such as ultralow-threshold current lasers [3]. However, the emission wavelength of the (In, Ga)As QDs grown on GaAs is limited to the $0.9-1.3 \mu \mathrm{m}$ range which does not match the usual wavelength for optical communications. In order to reach $1.55 \mu \mathrm{m}$, InAs QDs on InP are promising candidates [4]. Due to a $3.2 \%$ lattice mismatch of InAs on InP(001), elastic strain relaxation takes place above a certain critical thickness via a change of morphology from two-dimensional (2D) to three-dimensional (3D). Much of the research developed on self-organized growth of InAs on InP substrates is devoted to quantum island (QI) formation [4-7]. Among them, the growth on vicinal surfaces allows a lateral preferential growth at the surface step edges. Few studies of InAs QDs formation on misoriented (001) InP substrates have been reported [8-10]. In this work we report on the optical

\footnotetext{
* Corresponding author.

E-mail address: salem@insa-lyon.fr (B. Salem).
}

anisotropy and the temperature-dependent photoluminescence (PL) measurements of InAs QIs grown on vicinal $2^{\circ} \mathrm{F}$ and $2^{\circ} \mathrm{B}(001) \mathrm{InP}$ substrates via solid-source molecular beam epitaxy (MBE).

\section{Experimental details}

The samples investigated in this study were grown by solid-source MBE in a Riber 2300 reactor. InAs selfassembled QIs were grown on semi-insulating $\operatorname{InP}(001)$, simultaneously on $2^{\circ}$ off miscut angle towards [110] direction and $2^{\circ}$ off miscut angle towards [010] direction substrates. Before the growth, the substrates were heated up to $535^{\circ} \mathrm{C}$ for a few minutes in order to remove the native oxide. Then a 300 -nm-thick InP buffer was grown at $480^{\circ} \mathrm{C}$ at $1 \mu \mathrm{m} / \mathrm{h}$ growth rate using a phosphorus pressure equal to $1 \times 10^{-5}$ Torr. Three monolayers (ML) of InAs were grown at $520^{\circ} \mathrm{C}$ with a reduced growth rate of $0.25 \mu \mathrm{m} / \mathrm{h}(0.22 \mathrm{ML} /$ s) and an arsenic pressure fixed at $4 \times 10^{-6}$ Torr. The 3D growth onset is observed by reflection high electron energy diffraction (RHEED) at 1.8ML. Uncapped islands were imaged using ex situ atomic force microscopy (AFM), using a Park Scientific Instruments microscope, model CP, operating in the contact mode [13]. In order to characterize 
the carrier confinement in these QIs with PL measurements, the samples were held $10 \mathrm{~s}$ under arsenic pressure at growth temperature and then were covered with a 40 -nm-thick InP layer grown at $0.25 \mu \mathrm{m} / \mathrm{h}$ using a phosphorus pressure of $4 \times 10^{-6}$ Torr and finally with a 260 -nm-thick InP cap layer grown at $1 \mu \mathrm{m} / \mathrm{h}$. The PL spectra were obtained in the 8-300 $\mathrm{K}$ temperature range. The $\mathrm{PL}$ was excited using either the $514.5 \mathrm{~nm}$ line of an $\mathrm{Ar}^{+}$-ion laser or a $1064 \mathrm{~nm}$ line of a YAG laser. The PL emission was dispersed by a high resolution grating spectrometer and detected by a $77 \mathrm{~K}$ cooled Ge photodetector using a conventional lock-in technique. The polarization measurements were performed on the PL emission normal to the surface via a GlanThompson near infrared polarizer at the entrance slit of the monochromator followed by a quarter wave plate in order to get the PL signal independent of any light polarization effect of the optical system response.

\section{Results and discussion}

\subsection{Temperature-dependent PL measurement}

Fig. 1(a) shows the PL spectra measured at several temperatures for the $2^{\circ} \mathrm{B}$ sample excited with an $\mathrm{Ar}^{+}$-ion laser. The excitation power is $200 \mathrm{~mW}$. The PL spectrum at $8 \mathrm{~K}$ shows a broad luminescence peak at $0.834 \mathrm{eV}$; the peak has an asymmetric shape with a tail at the high-energy side. The full width at half maximum (FWHM) of the PL peak is
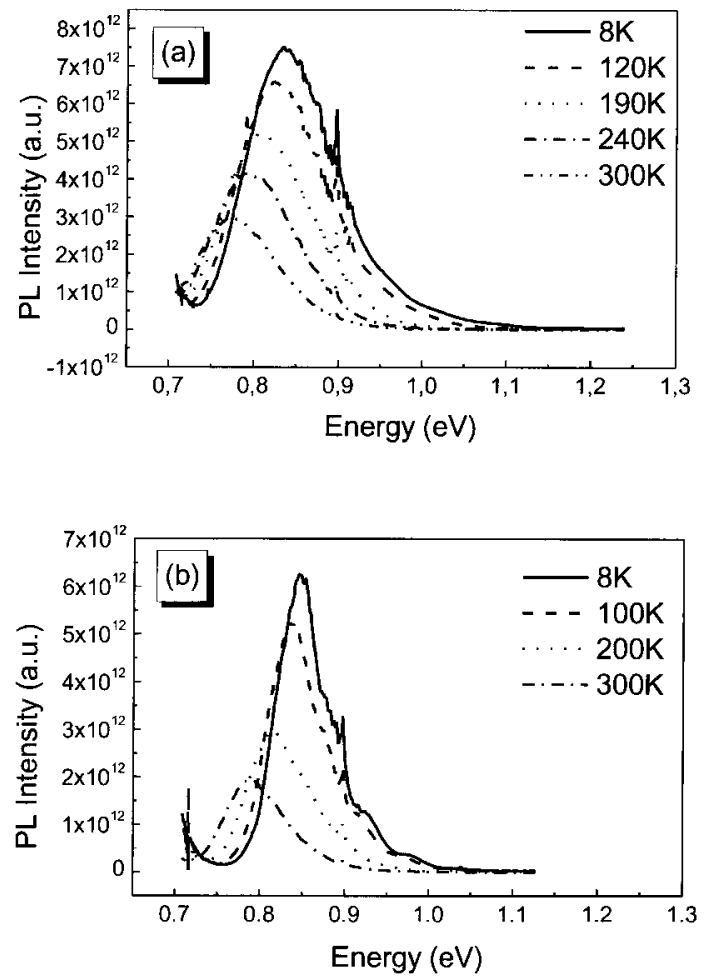

Fig. 1. PL spectra at several temperatures of the $2^{\circ} \mathrm{F}$ sample (a) and $2^{\circ} \mathrm{B}$ sample (b). approximately $115 \mathrm{meV}$. In order to study band filling phenomena, which may affect PL spectra shape due to the presence of excited states in the QIs, the linearity of the PL intensity with excitation power density has been measured, at $8 \mathrm{~K}$, from 0.6 to $3100 \mathrm{~W} / \mathrm{cm}^{2}$. The broad PL peak could rather originate from the size inhomogeneity of the InAs QIs. Indeed the smaller InAs QIs would emit at the higher energy side of the broad and the larger InAs QIs at the lower energy side. Therefore, the asymmetric shape of the PL peak with a high-energy tail would indicate that the larger InAs QIs are more numerous than the smaller InAs QIs. The PL spectrum at $8 \mathrm{~K}$ from the $2^{\circ} \mathrm{F}$ sample consists of several sharper bands (Fig. 1(b)). The measured line-widths of such individual lines are about only $45 \mathrm{meV}$, to be compared with the $115 \mathrm{meV}$ on the previous sample. No PL intensity transfer from low to high-energy peaks has been observed versus the excitation power density. This evidences that these individual lines can be attributed to the size fluctuation of the InAs QIs. No emission from the wetting layer is observed, indicating that carriers photogenerated diffuse quickly from the wetting layer to the adjacent InAs QIs.

The PL integrated intensity for the two QIs structures as a function of temperature is shown in Fig. 2. We clearly observe two different regimes in temperature dependence. The integrated intensity is quite stable in the $8-100 \mathrm{~K}$ range and decreases for temperatures higher than $100 \mathrm{~K}$. The decrease of the integrated PL emission at higher temperature is related to exciton dissociation, and consequent electron-hole pairs escape from the QIs. The temperature at which the exciton dissociation is observed is quite higher than that of quantum wells (QWs) and even other QDs reported elsewhere. The thermal activation energy of electron-hole emission from an InP barrier to the quantum dots was measured to be $79 \mathrm{meV}$ for both samples.

Finally, we show that the PL intensity remains very strong at room temperature, as much as $36 \%$ of its value at $8 \mathrm{~K}$ for the $2^{\circ} \mathrm{B}$ sample and $30 \%$ for the $2^{\circ} \mathrm{F}$ sample. This behavior suggests that the photo-generated carriers

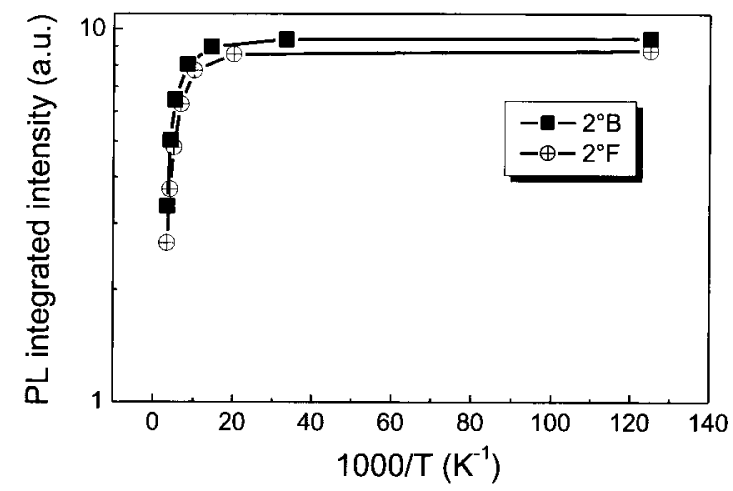

Fig. 2. Temperature dependence of the integrated PL intensity. The thermal-activation energy of electron-hole emission through an InP barrier calculated from the figure is measured at $79 \mathrm{meV}$. 
recombine mostly in the QIs without escaping to the barrier layer even at room temperature.

\subsection{Polarization photoluminescence studies}

PL polarization measurements were performed in the linear response regime with an excitation spot diameter of $300 \mu \mathrm{m}$. The degree of linear polarization $P$ of the emitted light is classically defined by the following equation:

$P=\frac{I_{[1 \mathrm{i} 0]}-I_{[110]}}{I_{[1 \overline{1} 0]}+I_{[110]}}$

where $I_{[1 \overline{1} 0]}$ and $I_{[110]}$ are the PL intensities along the two orthogonal directions [110] and [110]. No PL polarization anisotropy is observed for a InAs/InP quantum well (Fig. 3). On the $2^{\circ} \mathrm{F}$ sample, a strong anisotropy is observed; the two peaks observed at 0.964 and $1.038 \mathrm{eV}$ are related to the YAG laser. In fact, the PL peak intensities observed in the [110] direction of the polarizer are twice smaller than that observed in the [1 $1 \overline{1} 0]$ direction.

The degree of linear polarization of the $2^{\circ} \mathrm{F}$ sample is found to be around $40 \%$ (Fig. 4(a)). This result is the clear signature of quantum wires $(\mathrm{QWr})$. We also observed that the degree of linear polarization gradually decreases with the increase of the photon energy. This suggests that large size QWr have stronger optical anisotropy than small ones as was also evoked for InP/InGaP and InAs/GaAs(311) QDs $[11,12]$. In contrast, the degree of linear polarization of the $2^{\circ} \mathrm{B}$ misoriented sample is only $16 \%$ (Fig. 4(b)). These results reveal that the $2^{\circ}$ growth on miscut angle towards [010] substrate leads to grow more isotropic self-assembled InAs/InP QDs.

\section{Conclusion}

In conclusion, PL and polarization photoluminescence (PPL) spectroscopies have allowed to study the optical properties of InAs QIs grown on InP(001) and their dependence on substrate misorientation. We have shown that on the $2^{\circ}$ off miscut angle towards [010] substrate, we obtain a PPL signature related to quasi-isotropic InAs quantum dots

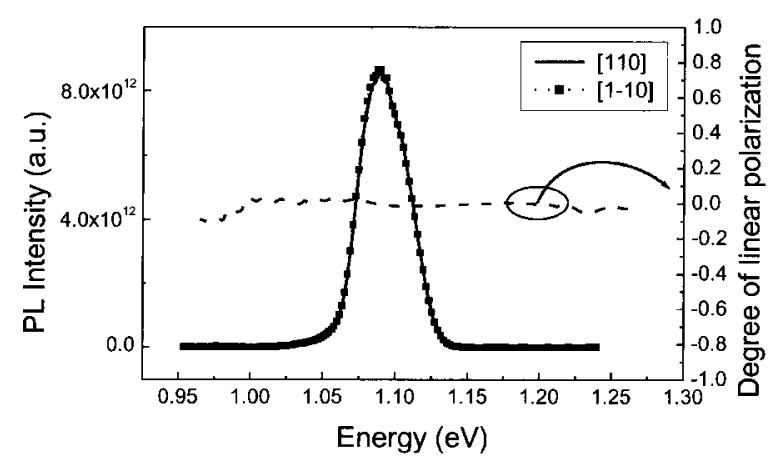

Fig. 3. Polarization PL spectra at $8 \mathrm{~K}$ and degree of linear polarization for the InAs/InP quantum well.
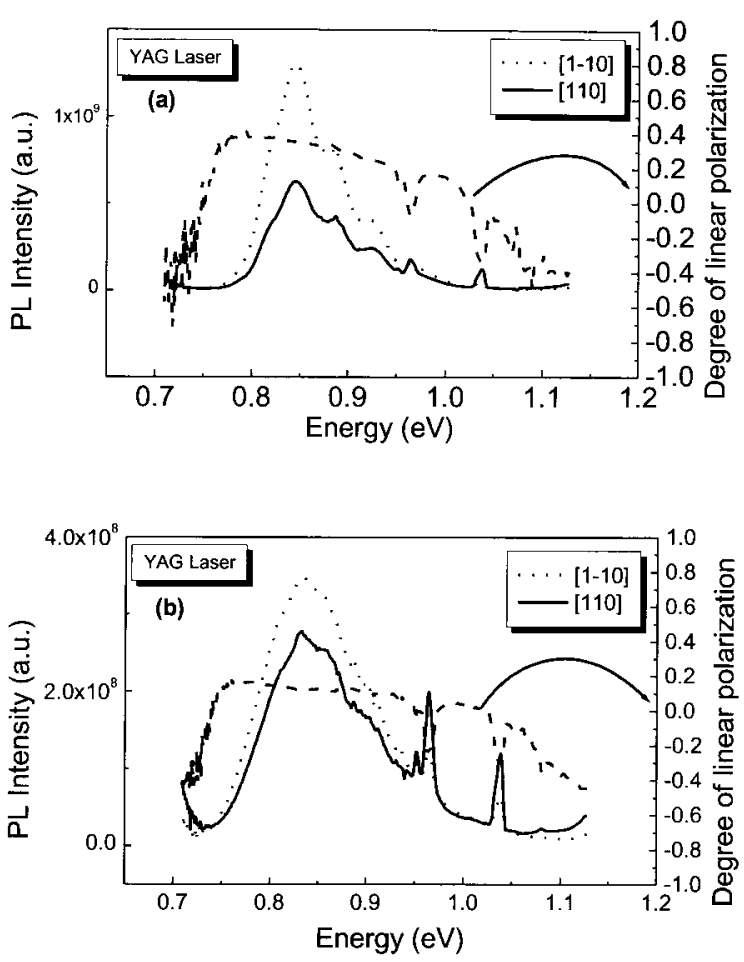

Fig. 4. Polarization PL spectra at $8 \mathrm{~K}$ and degree of linear polarization for the $2^{\circ} \mathrm{F}$ sample (a) and for the $2^{\circ} \mathrm{B}$ sample (b).

while a strong PPL signal corresponding to InAs quantum wires is observed on the substrate tilted $2^{\circ}$ off towards [110]. We have also shown a great stability of the integrated PL intensity in the $8-300 \mathrm{~K}$ temperature range according to a strong localization of photo-carriers in the InAs QIs grown on $\operatorname{InP}(001)$. Finally, the PL intensity remains very strong at room temperature, as much as $36 \%$ of its value at $8 \mathrm{~K}$ for the $2^{\circ} \mathrm{B}$ sample which corresponds to the best results obtained up to now on III-V quantum dots. Finally, this work points out that the optical properties of these InAs/InP QDs are very close to those needed for laser device applications and that PPL spectroscopy can efficiently be used as a way to check and estimate, just after growth, the wire shape or the isotropic shape of QIs.

\section{References}

[1] P.M. Petroff, S.P. DenBaars, Superlattices Microstruct. 15 (1994) 15.

[2] Y. Nabetani, T. Ishikawa, S. Noda, A. Sasaki, J. Appl. Phys. 76 (1994) 347.

[3] C. Weisbuch, B. Vinter, Quantum Semiconductor Structures, Fundamentals and Applications, Academic press, San Diego, 1991.

[4] S. Fafard, Z. Wasilewski, J. McCaffery, S. Raymond, S. Charbonneau, Appl. Phys. Lett. 68 (1996) 991.

[5] A. Rudra, R. Houdré, J.F. Carlin, M. Ilegems, J. Cryst. Growth 136 (1994) 278

[6] H. Marchand, P. Desjardins, S. Guillon, J.-E. Paultre, Z. Bougrioua, R.Y.-F. Yip, R.A. Masut, Appl. Phys. Lett. 71 (1997) 527.

[7] A. Ponchet, A. Le Corre, H. L'Haridon, B. Lambert, S. Salaün, Appl. Phys. Lett. 67 (1995) 1850. 
[8] R. Leonelli, C.A. Tran, J.L. Brebner, J.T. Graham, R. Tabti, R.A. Masut, S. Charbonneau, Phys. Rev. B 48 (1993) 11135.

[9] N. Lebouché-Girard, A. Rudra, E. Kapon, J. Cryst. Growth 175 (1997) 1210.

[10] P. Paki, R. Leonelli, L. Isnard, R.A. Masut, J. Appl. Phys. 86 (1999) 6789.

[11] M. Sugisaki, H.W. Ren, S. Nair, Phys. Rev. B 59 (1999) R5300.
[12] M. Henini, S. Sanguinetti, S.C. Fortina, E. Grilli, M. Guzzi, G. Panzarrini, L.C. Andreani, M.D. Upward, P. Moriarty, P.H. Beton, L. Eaves, Phys. Rev. B 57 (1998) R6815.

[13] B. Salem, J. Olivares, G. Guillot, G. Bremond, J. Brault, C. Monat, M. Gendry, G. Hollinger, F. Hassen, H. Maaref, Appl. Phys. Lett. 79 (2001) 4435 